9-2005

Increased risk of HIV in women experiencing physical partner violence in Nairobi, Kenya

Karoline Fonck

Leye Els

Nancy Kidula

Jeconiah Ndinya-Achola

Marleen Temmerman

Follow this and additional works at: https://ecommons.aku.edu/eastafrica_fhs_mc_obstet_gynaecol

Part of the Obstetrics and Gynecology Commons 


\title{
Increased Risk of HIV in Women Experiencing Physical Partner Violence in Nairobi, Kenya
}

\author{
Karoline Fonck, ${ }^{1,2}$ Leye Els, ${ }^{1}$ Nancy Kidula, ${ }^{1,2}$ Jeconiah Ndinya-Achola, ${ }^{2}$ \\ and Marleen Temmerman ${ }^{1,3}$
}

Received Sep. 4, 2003; accepted Jan. 25, 2005; Published online Aug. 25, 2005

As part of a study on etiology of sexually transmitted infections (STI) among 520 women presenting at the STI clinic in Nairobi, data on partner violence and its correlates were analyzed. Prevalence of lifetime physical violence was $26 \%$, mainly by an intimate partner (74\%). HIV seropositive women had an almost twofold increase in lifetime partner violence. Women with more risky sexual behavior such as early sexual debut, number of sex partners, history of condom use and of STI, experienced more partner violence. Parity and miscarriage were associated with a history of lifetime violence. We found an inverse association between schooling and level of violence. Six percent of the women had been raped. Gender-based violence screening and services should be integrated into voluntary counseling and testing programs as well as in reproductive health programs. Multi-sector approaches are needed to change prevailing attitudes towards violence against women.

KEY WORDS: partner violence; HIV; Kenya.

\section{INTRODUCTION}

Violence against women is a major public health problem, resulting in injuries and other short and long term health consequences, including mental illness and complications of pregnancy (WHO, 1998). Over the past decade, recognition of the scope and significance of domestic violence has increased, but because of the sensitivity of the subject, violence is almost universally under-reported. Nevertheless, available data suggest that globally, millions of women are experiencing violence or are living with its consequences (Watts and Zimmerman, 2002). One of the most common forms of violence against women is that perpetrated by a husband or intimate male

\footnotetext{
${ }^{1}$ International Centre for Reproductive Health, Ghent University, De Pintelaan 185 P3, 9000 Ghent, Belgium.

${ }^{2}$ University of Nairobi, Department of Medical Microbiology, P.O. Box 19676, Nairobi, Kenya.

${ }^{3}$ Correspondence should be directed to Marleen Temmerman, International Centre for Reproductive Health, Ghent University, De Pintelaan 185 P3, 9000 Ghent, Belgium; e-mail: marleen. temmerman@ugent.be.
}

partner. According to a global review of over 50 population-based surveys over the past 16 years, between $10 \%$ and $60 \%$ of adult women have been hit or otherwise physically assaulted by an intimate male partner at some point in their lives. This same review indicates that between $3 \%$ and $52 \%$ of women reported physical violence in the previous year (Heise et al., 1999). Research has shown that physical violence is accompanied by sexual abuse in a third to over half of the cases (WHO, 2002).

An emerging health concern is that women undergoing physical violence by a partner are also more likely to exhibit a spectrum of unhealthy sexual behaviors, attitudes, beliefs and norms (Wingood et al., 2001). Women who are victims of physical abuse may not practice appropriate measures to prevent transmission of HIV and other sexually transmitted infection. Studies indicate that lack of consistent condom use among women can be attributed to low sexual relationship power (Pulerwitz et al., 2002). Studies from Africa show an increased risk of violence when the man is HIV positive (Van Der Straten et al., 1998) or when the woman perceives herself to be at 
increased risk of acquiring HIV from the man (Coker and Richter, 1998). Furthermore, women who disclose their HIV status to their partner and women who negotiate condom use risk the threat of domestic violence (Gaillard et al., 2002; Wingood and DiClemente, 1997).

As a growing body of evidence is highlighting the magnitude of the problem of domestic violence in developing countries, data on its prevalence in SubSaharan Africa is limited as is the understanding of the underlying determinants of this type of violence in the region. While the available information on the occurrence of partner violence in Kenya is scarce and often anecdotic, there are nevertheless indications that the prevalence is quite high. Well known is the HIV seroprevalence in the general population in Kenya, estimated at $14 \%$ at the time of the study (UNAIDS, 1998).

This paper reports the occurrence of lifetime physical partner violence and its correlates in a group of women presenting at the Sexually Transmitted Infections (STI) referral clinic in Nairobi, and the association between this type of violence and HIV seroprevalence.

\section{METHODS}

\section{Study Population}

A total of 520 women were enrolled. A detailed description on the characteristics of these women is published elsewhere (Fonck et al., 2000b).

\section{Measures and Procedures}

This research was part of a study on the etiology and risk markers for STI among women attending the STI clinic in Nairobi, Kenya. Although this is a referral clinic, a large proportion of patients is selfreferred.

Enrolment took place between June 1996 and April 1997. After registration by the clinic clerks, patients were directed to one of the clinician's consultation rooms (including the study clinician), and this choice depended solely on the number of patients still queuing in front of those rooms. Selection was therefore not random but the best alternative in the given circumstances. Written informed consent was obtained from all participants. A trained research nurse was responsible for administering the stan- dardized pre-tested questionnaire in either English or Swahili, depending on the woman's preference, and also offering HIV pre-test counseling to each woman. Data collection included socio-demographic data, previous reproductive medical history, knowledge about STI and HIV, sexual behavior and the presence of genital symptoms. The interviews lasted between $30 \mathrm{~min}$ and $1 \mathrm{~h}$, in total confidentiality. Thereafter, the study physician performed a gynecological examination. Details on the laboratory procedures are published elsewhere (Fonck et al., 2000b). Women who accepted HIV testing were offered the results upon the return visit one week later, after post-test counseling by the same research nurse.

Several questions on the history of physical violence and rape were included in the questionnaire. The nurse asked about the occurrence of beating or rape in the community the woman lives in, if she knew of anyone who had been raped, and if she herself had ever in her life undergone this kind of violence, and if so, who the aggressor was. Several possible answers to the questions were pre-coded. For women who affirmed occurrence of such events, the nurse asked if she told others about it or if she had reported it to official instances.

\section{RESULTS}

Of the 520 women recruited in the main study, $137(26 \%)$ reported ever in their lifetime having been beaten and 30 women $(6 \%)$ had been raped. Of the women reporting a history of beating, the vast majority $(n=101,74 \%)$ was beaten by a partner, either by their current regular partner $(n=61)$, an ex-partner $(n=31)$ or a casual partner $(n=10)$. The other women experienced violence by a relative $(7 \%)$, a friend $(7 \%)$ or another person $(12 \%)$.

The mean age of the women with a history of partner violence $(n=101)$ was 27 years. The majority of the women $(64 \%)$ were married or cohabitating. About $60 \%$ of the women had 5 to 8 years of schooling. More than half of the women reported having no income. The mean number of pregnancies was 2.7 , while the mean number of children born was 1.8 . The mean number of miscarriage was 0.5 . Thirty nine $(39 \%)$ percent of the women was pregnant at the time of the interview.

The vast majority $(73 \%)$ reported only one sexual partner in the past three months, while 13 women had 2 or more sexual partners, of whom eight women had 2 or more new sexual partners in the past three months. The remainder had no sexual partner during 
the past three months. A history of STI was reported by $44 \%$ of the women. Of all women who reported partner violence, $40 \%$ were HIV infected, with the highest seroprevalence rates in women aged 30 to 39 years $(50 \%)$.

Table I summarizes the correlates of lifetime physical violence. Women aged 30 to 39 reported significantly more lifetime partner violence than

Table I. Correlates of Lifetime Physical Partner Violence, Univariate Analysis

\begin{tabular}{|c|c|c|c|c|}
\hline Characteristic & $n$ & $\%$ Violence & OR & $95 \% \mathrm{CI}$ \\
\hline \multicolumn{5}{|l|}{ Age (years) } \\
\hline$<30$ & 408 & 18 & 1 & \\
\hline $30-39$ & 89 & 27 & 1.7 & $1.0-2.0$ \\
\hline$\geq 40$ & 23 & 22 & 1.3 & $0.5-3.6$ \\
\hline \multicolumn{5}{|l|}{ Marital status } \\
\hline Single & 162 & 12 & 1 & \\
\hline $\begin{array}{l}\text { Married/ } \\
\text { cohabitating }\end{array}$ & 288 & 22 & 2.0 & $1.2-3.4$ \\
\hline $\mathrm{S}-\mathrm{D}-\mathrm{W}^{a}$ & 56 & 30 & 3.1 & $1.5-6.5$ \\
\hline \multicolumn{5}{|l|}{ Education (Years) } \\
\hline Up to primary & 293 & 23 & & \\
\hline $\begin{array}{l}\text { Secondary and } \\
\text { more }\end{array}$ & 227 & 15 & 0.6 & $0.4-0.9$ \\
\hline \multicolumn{5}{|l|}{ Income $^{b}$} \\
\hline 1-2000 Ksh & 343 & 18 & & \\
\hline$\geq 2000 \mathrm{Ksh}$ & 177 & 22 & 1.3 & $0.8-2.0$ \\
\hline \multicolumn{5}{|l|}{$\begin{array}{l}\text { Number of } \\
\text { pregnancies }\end{array}$} \\
\hline $0-2$ & 362 & 16 & & \\
\hline$>2$ & 158 & 27 & 2.0 & $1.3-3.1$ \\
\hline \multicolumn{5}{|l|}{ Parity } \\
\hline $0-1$ & 345 & 14 & & \\
\hline$>1$ & 175 & 30 & 2.6 & $1.6-4.0$ \\
\hline \multicolumn{5}{|l|}{ Miscarriage } \\
\hline No & 500 & 18 & & \\
\hline Yes & 20 & 45 & 3.6 & $1.5-9.0$ \\
\hline \multicolumn{5}{|c|}{ Age at first sex (years) } \\
\hline$<15$ & 56 & 20 & 1 & \\
\hline $15-17$ & 184 & 26 & 1.4 & $0.7-3.0$ \\
\hline $18-19$ & 147 & 21 & 1.1 & $0.5-2.4$ \\
\hline$\geq 20$ & 129 & 9 & 0.4 & $0.2-0.9$ \\
\hline \multicolumn{5}{|c|}{$\begin{array}{l}>1 \text { sex partner in past } \\
3 \text { months }\end{array}$} \\
\hline No & 462 & 18 & & \\
\hline Yes & 58 & 28 & 1.7 & $0.9-3.1$ \\
\hline \multicolumn{5}{|l|}{ Ever used condoms } \\
\hline No & 274 & 16 & & \\
\hline Yes & 246 & 23 & 1.6 & $1.0-2.4$ \\
\hline \multicolumn{5}{|l|}{ Ever STI } \\
\hline No & 356 & 16 & & \\
\hline Yes & 164 & 27 & 1.9 & $1.2-3.0$ \\
\hline \multicolumn{5}{|l|}{ HIV status } \\
\hline HIV- & 368 & 17 & & \\
\hline HIV+ & 152 & 26 & 1.8 & $1.1-2.8$ \\
\hline
\end{tabular}

${ }^{a}$ S-D-W: separated or divorced or widowed.

${ }^{b} 1 \mathrm{USD}=70 \mathrm{Ksh}$. younger women. Married women were twice as much at risk for partner violence than single women; women who were divorced, separated or widowed had a three fold higher risk of lifetime violence.

We found a strong relationship between schooling of the woman and lifetime partner violence, with a significant test for trend, indicating that the lower the schooling, the higher the probability of being beaten.

There was no correlation between income of the woman or her partner, and partner violence. We found a strong positive association between partner violence and number of pregnancies as well as with number of children born, but not with being pregnant at the time of the interview. Women who ever had a miscarriage reported an almost four fold increased risk of lifetime partner violence. We found no association between a history of stillbirth and violence, but the numbers are probably too small to detect any association.

Women with a history of partner violence were younger at their first sexual experience (17 vs. 17.7, $p<.05)$. Women who had started their sex life after the age of 20 years, experience partner violence half as much as women who did so before the age of 15 .

Women with more than one sex partner in the past three months and women who had ever used condoms were more subject to physical partner violence than other women. There was an almost two-fold increase in lifetime partner violence among women with a history of STI. HIV seropositive women had experienced almost twice as much physical violence than seronegative women. It has to be noted that most women in this study were not aware of their HIV serostatus at the time of the interview. After logistic regression, including age, number of partners and schooling, HIV remains significantly associated with partner violence.

Thirty women $(6 \%)$ had ever been raped. Only one woman reported rape by the current regular partner, while 7 ( $23 \%$ ) were raped by a casual partner, $4(13 \%)$ by a relative, $1(3 \%)$ by a friend and $17(57 \%)$ by other people. Only $63 \%$ of them had told someone else about the rape. Rape victims were also significantly more beaten up ( $25 \%$ vs. $47 \%$, OR 2.6, 95\% CI 1.2-5.5).

\section{DISCUSSION}

The current results underscore not only the existence of the problem of violence against women in 
Nairobi, but also the association between partner violence and HIV infection in women.

Some studies on domestic violence in Africa reported somewhat higher levels of violence, $43 \%$ and $40 \%$ of women in Zimbabwe (Watts et al., 1998) and Uganda (Blanc et al., 1996) respectively experienced physical violence. Similar rates of domestic violence were reported by other studies: $20 \%$ in Rwanda (Van Der Straten et al., 1998), 25\% in South Africa (Jewkes et al., 2001) and 30\% in Uganda (Koenig et al., 2003). It has to be noted that these studies were all population based. Recall bias may be one explanation for the relatively low prevalence of violence in our study, as we investigated life time violence. Women may only remember more severe beatings, with under-reporting of the less severe occurrences of violence. Cultural acceptance of gender based violence in general and partner violence in particular may be another factor of under-reporting. Indeed, domestic violence may be regarded as normal, and some African traditions allow occasional "disciplining" of wives with violence being accepted as part of marriage and wife beating is often even considered a sign of love (Heise et al., 1999; Kiragu, 1995).

An important finding of our study was the strong association between positive HIV serology of the woman and lifetime history of physical partner violence, underscoring the link between both epidemics. As physical violence is often accompanied by sexual violence, women with a history of any type of violence may be at increased risk for unintended pregnancy, adverse pregnancy outcomes, and STI including HIV. A similar association has recently been reported from a voluntary counseling and testing (VCT) clinic in Tanzania (Maman et al., 2002). It can be assumed that women seeking VCT services do feel at risk for HIV infection. Most women in our study however were attending mainly for vaginal discharge during pregnancy and reported very little risky sexual behavior (Fonck et al., 2000b).

The women in our study were not aware of their HIV status at the time of the interview; hence the reported violence can not be linked to disclosure of test results, as often reported (Temmerman et al., 1995, Gaillard et al., 2002). The fear of this violence, including being abandoned by the partner, discourages women to undergo VCT as well as to disclose test results, undermining the possible preventive activities that may result from VCT. A study in Uganda showed a strong association between women's perception of their male partner's HIV risk and the women's risk of domestic violence (Koenig et al.,
2003). Hence, it is possible that although women do not know their HIV status, they may have a good perception of their partner's and hence their own HIV status.

Other studies identified a strong association between having a physically abusive partner and less condom use among women attempting to negotiate safer sex (Wingood and DiClemente, 1997). We however found that women who had ever used condoms had also experienced more partner violence. In this society women generally cannot negotiate safe sex, hence the women that report condom use may be somewhat different from their peers, and condom use may in this setting be a marker for high risk behavior, including multiple partners or sex work. Only a few women in our study report more than one sex partner in the past three months, which may be an indication of commercial sex work (we did not specifically ask for engagement in sex work). The vast majority of the women however had sexual relationships with only one person, usually their regular partner.

Our study reconfirmed the inverse relation between schooling and levels of violence, as demonstrated in many studies around the world, indicating that high levels of female empowerment seem to be protective against (partner) violence (Martin et al., 1999; Jewkes, 2002).

We found a strong relation between violence and the number of pregnancies as well as with history of miscarriage. Violence against pregnant women is highly prevalent world-wide (Gazmararian et al., 1996) and is associated with detrimental outcomes to mothers and infants (Cokkinides et al., 1999; AslingMonemi et al., 2003). Although we cannot establish the causal link, the association we found between violence and history of miscarriage, was striking. Similarly to other studies (Martin et al., 1999) we also demonstrated that the number of children born was associated with violence against the woman, although this association disappears after controlling for age of the woman.

Our study has two potential limitations. Firstly, the prevalence of violence may have been underestimated. We only included questions on physical violence although other studies suggest a significant overlap between physical violence and other forms of violence namely psychological and sexual (WHO, 2002). Secondly, the sample in this study may not be representative for the general female population of Nairobi. Other studies in this setting however indicated that the women seen in this STI referral clinic are not very different from women attending 
peripheral health centers (Fonck et al., 2000a). Although being a STI referral clinic, many women consult here for abnormal vaginal discharge mainly during pregnancy, and do not represent a population at high risk for STI or HIV.

The results of our study have some important implications for intervention programs. Apart from the direct consequences of physical violence on women and their offspring, there is indirect evidence that gender-based violence may represent a significant factor in women's vulnerability to HIV acquisition in settings such as Nairobi. Gender-based violence screening and services should be integrated into voluntary counseling and testing (VCT) programs and should also be addressed at antenatal care clinics, child-wellbeing centers, and during postabortion care.

However, progress in reducing domestic violence is unlikely to be achieved without significant changes in prevailing individual and community attitudes towards domestic violence. Therefore, any intervention strategy should not only encompass the health sector, but also extend beyond that to include many other sectors of society and government.

\section{REFERENCES}

Asling-Monemi, K., Peña, R., Ellsberg, M. C., and Persson, L. A. (2003). Violence against women increases the risk of infant and child mortality: A case-referent study in Nicaragua. Bulletin of WHO, 8, 10-18.

Blanc, A., Wolff, B., Gage, A., Ezeh, A., Neema, S., and Ssekamatte-Ssebuliba, J. (1996). Negotiating reproductive outcomes in Uganda. Calverton, Maryland: Macro International Inc. and Institute of Statistics and Applied Economics [Uganda].

Coker, A. L., and Richter, D. L. (1998). Violence against women in Sierra Leone: Frequency and correlates of intimate partner violence and forced sexual intercourse. African Journal of Reproductive Health, 2, 61-72.

Cokkinides, V., Coker, A., Sanderson, M., Addy, C., and Bethea, L. (1999). Physical violence during pregnancy: maternal complications and birth outcomes. Obstetrics and Gynecology, 93, 661-666.

Fonck, K., Kidula, N., Jaoko, W., Estambale, B., Claeys, P., Kirui, P., and Temmerman, M. (2000a). Validity of the vaginal discharge algorithm among pregnant and non-pregnant women in Nairobi, Kenya. Sexually Transmitted Infections, 76, 33-38.

Fonck, K., Kidula, N., Kirui, P., Ndinya-Achola, J., Bwayo, J., Claeys, P., and Temmerman, M. (2000b). Pattern of sexually transmitted diseases and risk factors among women attending an STD referral clinic in Nairobi, Kenya. Sexually Transmitted Diseases, 7, 417-423.

Gaillard, P., Melis, R., Mwanyumba, F., Claeys, P., Muigai, E., Mandaliya, K., Bwayo, J., and Temmerman, M. (2002). Vul- nerability of women and HIV infection in an African setting: Lessons for the implementation of perinatal interventions to reduce mother-to-child HIV transmission. AIDS, 16, 937-939.

Gazmararian, J., Lazorick, S., Spitz, A., Ballard, T., Saltzman, L., and Marks, J. (1996). Prevalence of violence against pregnant women. Journal of the American Medical Association, 275, 1915-1920.

Heise, L., Ellsberg, M., and Gotemoeller, M. (1999). Ending violence against women: Population reports volume 27, number 4. Baltimore: Johns Hopkins University, School of Public Health.

Jewkes, R. (2002). Intimate partner violence: Causes and prevention. Lancet, 359, 1423-1429.

Jewkes, R., Penn-Kekana, L., Levin, J., Ratsaka, M., and Schrieber, M. (2001). Prevalence of emotional, physical, and sexual abuse of women in three South African provinces. South African Medical Journal, 91, 421-428.

Kiragu, J. (1995). HIV prevention and women's rights: Working for one means Working for both. AIDScaption, 2, 40-46.

Koenig, M. A., Lutalo, T., Zhao, F., Nalugoda, F., WabwireMangen, F., Kiwanuka, N., Wagman, S. D., Wawer, M., and Gray, R. (2003). Domestic violence in rural Uganda: Evidence from a community-based study. Bulletin of WHO, 81, 53-60.

Maman, S., Mbwambo, J. K., Hogan, N. M., Kilonzo, G. P., Campbell, J. C., Weiss, E., and Sweat, M. D. (2002). HIVpositive women report more lifetime partner violence: Findings from a voluntary counseling and testing clinic in Dar es Salaam, Tanzania. American Journal of Public Health, 92, 1331-1337.

Martin, S. L., Tsui, A. O., Maitra, K., and Marinshaw, R. (1999). Domestic violence in Northern India. American Journal of Epidemiology, 150, 417-426.

Pulerwitz, J., Amaro, H., De Jong, W., Gortmaker, S. L., and Rudd, R. (2002). Relatinship power, condom use and risk among women in the USA. AIDS Care, 14, 798-800.

Temmerman, M., Ndinya-Achola, J., Ambani, J., and Piot, P. (1995). The right not to know HIV test results. Lancet, 345 , 969-970.

UNAIDS (1998). Epidemiologival fact sheet on HIV/AIDS and sexually transmitted diseases. Geneva, World Health Organization.

Van Der Straten, A., King, R., Grinstead, O., Vittinghoff, E., Serufilira, A., and Allen, S. (1998). Sexual coercion, physical violence, and HIV infection among women in steady relationships in Kigali, Rwanda. AIDS and Behavior, 2, 6173.

Watts, C., Keough, E., Ndlovu, M., and Kwaramba, R. (1998). Withholding of sex and forced sex: Dimensions of violence against Zimbabwean women. Reproductive Health Matters, 6 , 57-65.

Watts, C., and Zimmerman, C. (2002). Violence against women: Global scope and magnitude. Lancet, 359, 1232-1237.

WHO (1998). Violence against women. Geneva: WHO/FRH/ WHD.

WHO (2002). World Health Report on Violence and Health. Geneva.

Wingood, G., and DiClemente, R. (1997). The effects of an abusive primary partner on the condom use and sexual negotiation practices of African-American women. American Journal of Public Health, 87, 1016-1018.

Wingood, G., DiClemente, R., McCree, D., Harrington, K., and Davies, S. (2001). Dating violence and the sexual health of black adolescent females. Pediatrics, 107, E72. 